\title{
MATLAB-CST Interfacing for a Micro-strip Patch Antenna
}

\author{
Garima*, Aarti Bansal and Surbhi Sharma
}

Department of Electronics and Communication Engineering, Thapar University, Patiala - 147004, Punjab, India; garima.01sethi@gmail.com, bansal.virgo@gmail.com, surbhisharma26@yahoo.com

\begin{abstract}
Objectives: To present an overview on interfacing of MATLAB and commercial electromagnetic software packages (such as CST microwave studio). Methods/Statistical Analysis: This type of interfacing requires a scripting language interface termed as VBA script. An example for the design of an inset microstrip patch antenna is demonstrated in this paper using VBA. The controlling of CST microwave studio is done using MATLAB which calls microstrip patch antenna design along with its performance parameters such as $S_{11}$ parameter, VSWR, power requirement, radiation pattern, return losses etc. Findings: The interface created between CST and MATLAB worked well and antenna parameters can be called in MATLAB to operate on them. Improvements: Further optimization algorithm can be performed on this in order to get optimized real time performance of antenna.
\end{abstract}

Keywords: CST Microwave Studio (MWS), MATLAB, Microstrip Patch Antenna, PSO, VBA

\section{Introduction}

MATLAB (Matrix laboratory) is a ubiquitous tool employed to allow matrix manipulations, implementation of algorithms, signal processing, creation of user interfaces and graphics software package 1 . It is a general purpose application comprises powerful analysis tool for design, analysis and control which facilitates esoteric applications like antenna design, are done using special commercial electromagnetic software. The MATLAB commercial electromagnetic solver interface 2 becomes critical in number of applications such as in numerical optimization. The systematic instruction to interface MATLAB with CST microwave studio ${ }^{2}$ using Visual Basic for Application is demonstrated in this paper. For the above interfacing, an example from the wireless communication technology is taken. As in the past years, there is a fast evolution in the wireless research and development activity. Due to this advancement the size of the antenna is going smaller day by day, the performance is also improved. With the ease of installation, the cost of antenna also reduced to a great extent. In today's world of wireless communication technology, the desire for the compact size ${ }^{3}$, planner structure, low profile, low weight and easy fabrications are being fulfilled by the microstrip patch antenna ${ }^{4}$. Basic structure of patch antenna is shown in Figure 1. This type of antenna can be integrated easily with passive and active components ${ }^{\underline{5}}$. It is also more versatile rather than conventional antennas which do not offers diversity function in operating frequency, radiation pattern and polarization to mobile communication in a single antenna $\mathrm{a}^{4}$. It has a operating range of frequencies from $1 \mathrm{GHz}$ to $100 \mathrm{GHz}$. But the inherent narrow Bandwidth and Low efficiency are the well known demerits of the microstrip patch antenna which can be optimized by various techniques ${ }^{\underline{6}}$.

Because of the above stated advantages, microstrip patch antennas are employed in various fields like The Wireless and Mobile communications, Biomedical equipments, Radio Frequency Identification (RFID),

*Author for correspondence 
Automotive industry, Ultra Wide band systems, Military and commercial applications such as Radar and satellite communication $\underline{5.7 .7}$.

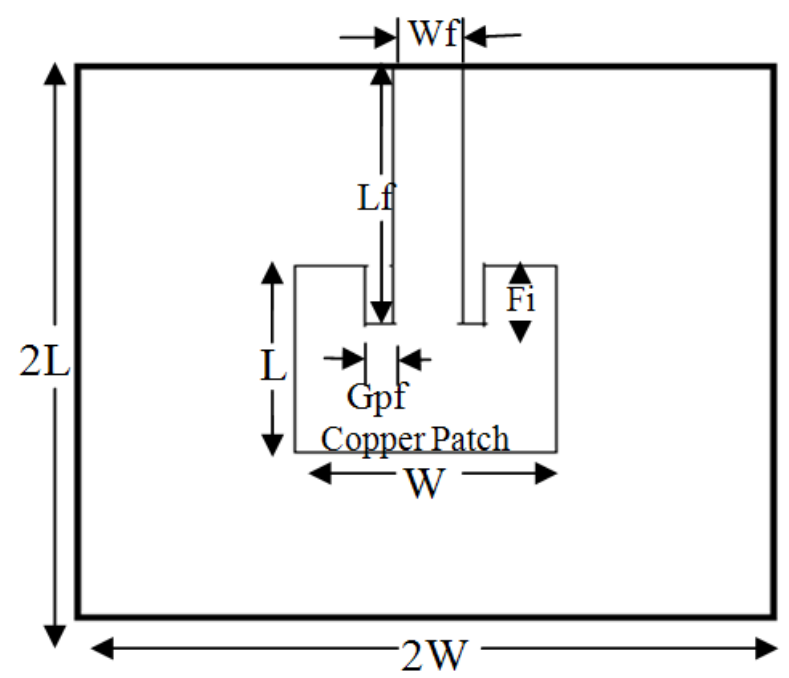

Figure 1. Top view of inset microstrip patch antenna ${ }^{8}$.

The paper is organized as follows: The Section 1 describes us the brief introduction about MATLABCST interfacing using an inset microstrip patch antenna. Section 2 describes the various mathematical formulas employed to calculate the dimensions of patch antenna. In Section 3 the antenna design specifications (both known and calculated antenna parameters) are depicted. In Section 4 we describe the VBA interfacing architecture which helps us to get familiar with VBA editor, different files generated during MATLAB-CST interfacing to get the simulated results. The last section concludes the paper along with its future scopes.

\section{Mathematical Formulation to Calculate Dimensions of Microstrip Patch Antenna}

To calculate the dimensions of ground plane and patch of the antenna (that is length and width), the following mathematical formulas are inured ${ }^{8-10}$.

- Width of the patch:

$$
W=\left(\frac{c}{2 f r}\right)\left(\frac{\epsilon_{r}+1}{2}\right)^{-.5}
$$

Where $\mathrm{c}=3 \times 10^{8} \mathrm{~ms}^{-1}, \varepsilon_{\mathrm{r}}=4.3, \mathrm{f}_{\mathrm{r}}=1.8 \mathrm{Ghz}$
- Effective dielectric constant:

$$
\in_{\text {eff }}=\left(\frac{\in_{r}+1}{2}\right)+\left(\frac{\in_{r}-1}{2}\right)\left(1+\frac{12 h}{W}\right)^{-.5}
$$

at $\mathrm{h}=4.5 \mathrm{~mm}$

- Length Extension:

$\Delta L=.412 h\left(\frac{\epsilon_{\text {eff }}+.3}{\epsilon_{\text {eff }}+.258}\right)\left(\frac{\left(\frac{W}{h}\right)+.264}{\left(\frac{W}{h}\right)+.8}\right)$

- Length of Rectangular Microstrip Patch:

$$
L=\left(\frac{c}{2 f r \sqrt{\epsilon_{e f f}}}\right)
$$

- Length and Width of Ground Plane:

$$
\begin{gathered}
L g=2 L \\
W g=2 W
\end{gathered}
$$

\section{Antenna Design Specifications}

Before we describe our technical contributions, we first introduce the notations and terms adopted throughout this paper. The parameters such as resonant frequency $\left(\mathrm{f}_{\mathrm{r}}\right)$, dielectric constant $\left(\epsilon_{\mathrm{r}}\right)$, substrate thickness $(\mathrm{h})$ are employed to calculate the geometrical dimensions of substrate and ground plane of the antenna. Some of the known antenna parameters are given in Table 1.

Table 1. Known antenna parameters

\begin{tabular}{|l|l|l|}
\hline S.NO & Antenna parameters & Data \\
\hline 1 & Resonant frequency $\left(\mathrm{f}_{\mathrm{r}}\right)$ & $1.8 \mathrm{GHz}$ \\
\hline 2 & Dielectric constant $\left(\epsilon_{\mathrm{r}}\right)$ & 4.3 \\
\hline 3 & Substrate thickness $(\mathrm{h})$ & $4.5 \mathrm{~mm}$ \\
\hline
\end{tabular}

Using above stated mathematical formulas and antenna parameters, the geometrical dimensions of substrate, patch and ground plane of antenna are calculated ${ }^{\underline{8}}$ as presented in Table 2. In order to meet the antenna design criteria these calculated geometrical dimensions are applied. Figure 2 shows the side view of patch antenna. The patch of the antenna is fed by a $50 \Omega$ microstrip feed line. 
Table 2. Calculated parameters

\begin{tabular}{|l|l|l|}
\hline S. NO & Antenna parameter & Data $(\mathbf{m m})$ \\
\hline 1 & Patch length (L) & 38 \\
\hline 2 & Patch Width (W) & 51 \\
\hline 3 & Ground plane length $(\mathrm{Lg})$ & 76 \\
\hline 4 & Ground plane Width $(\mathrm{Wg})$ & 102 \\
\hline
\end{tabular}

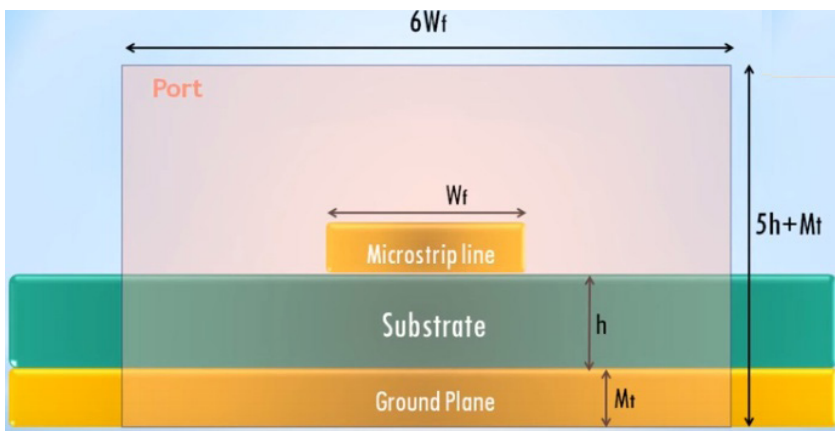

Figure 2. Side view of microstrip patch antenna ${ }^{8}$.

\section{Interfacing via VBA Script}

In order to meet the requirement for creating a powerful design and system analysis environment, MATLAB is used to control commercial electromagnetic software. The interfacing between MATLAB and commercial software is created via a scripting language (VBA script) ${ }^{11}$ as shown in Figure 3. A VBA script incorporates a set of instruc- tions written in a scripting language in the form of a text file. CST is accessed by MATLAB as shown in Figure 4.

In order to do interfacing between MATLAB and CST, the concept of client and server comes into picture. Both the software can act as server and client depending upon the application. Here we are controlling CST using MATLAB so, CST will act as server and MATLAB as client $\frac{1.2}{2}$. CST offers Command Line option for invoking VBA via external programs (Windows, MATLAB etc). The above method becomes inconvenient when multiple commands are to be executed. Our method comprises a single command line:

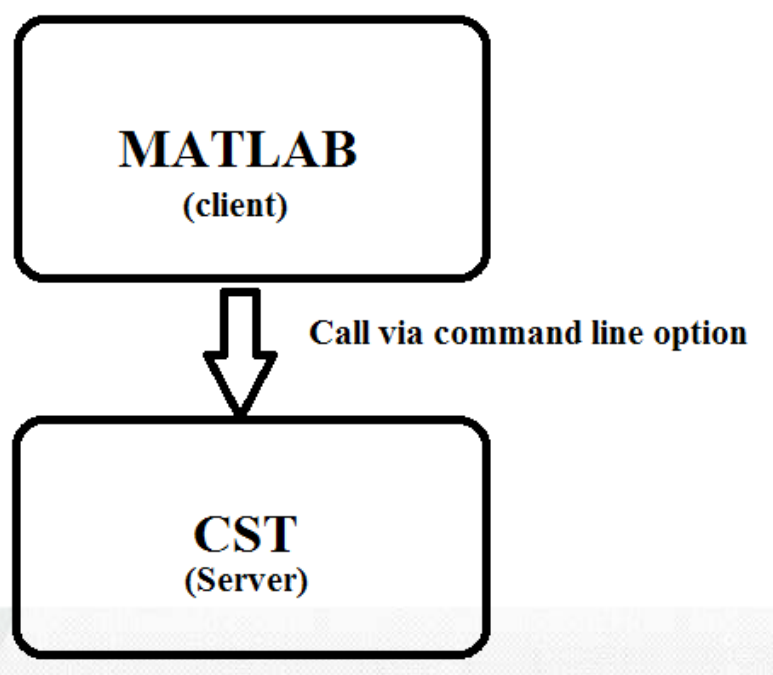

Figure 4. Calling CST using MATLAB $\stackrel{1,2}{ }$.

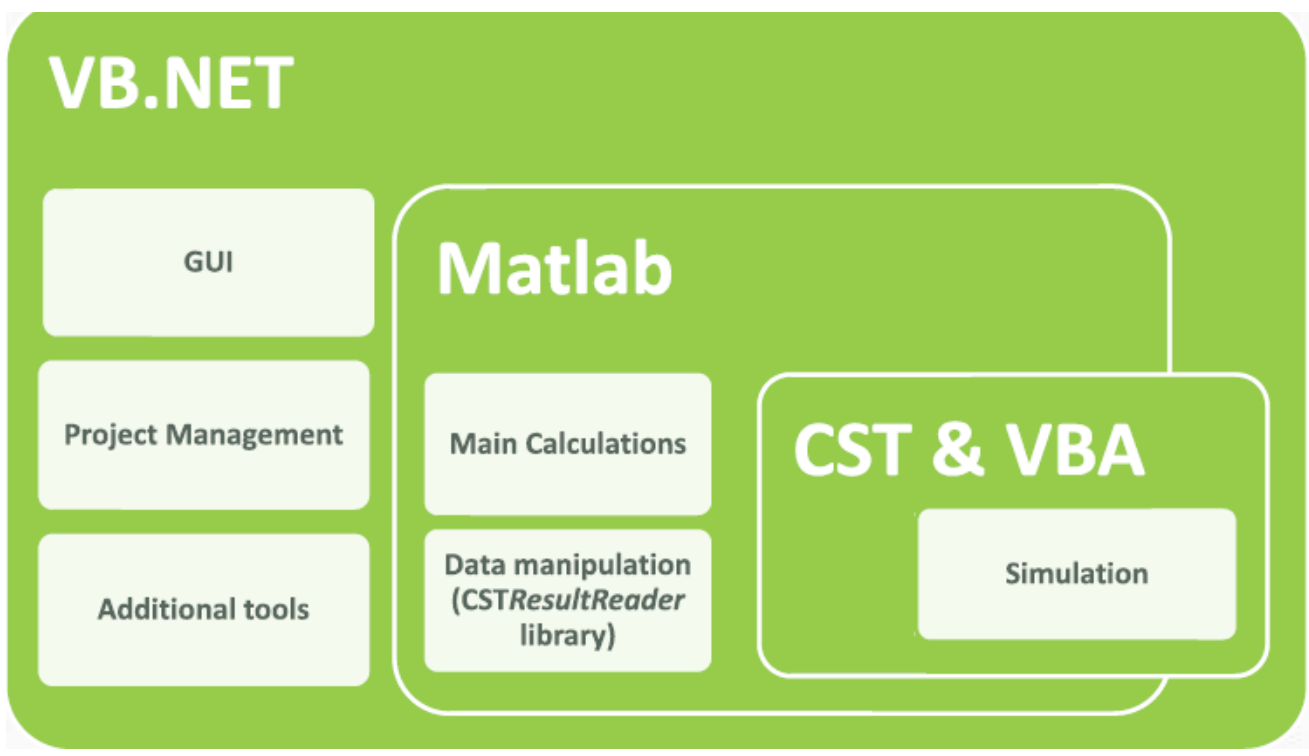

Figure 3. VBA Interfacing Architecture ${ }^{11}$. 
! (“c: \program files(x86)\CST STUDIO SUITE 2015\CST DESIGN ENVIRONMENT.exe-m|c:|test1.bas”)

The auxiliary script is written in real time and using the user input its internal content is determined.

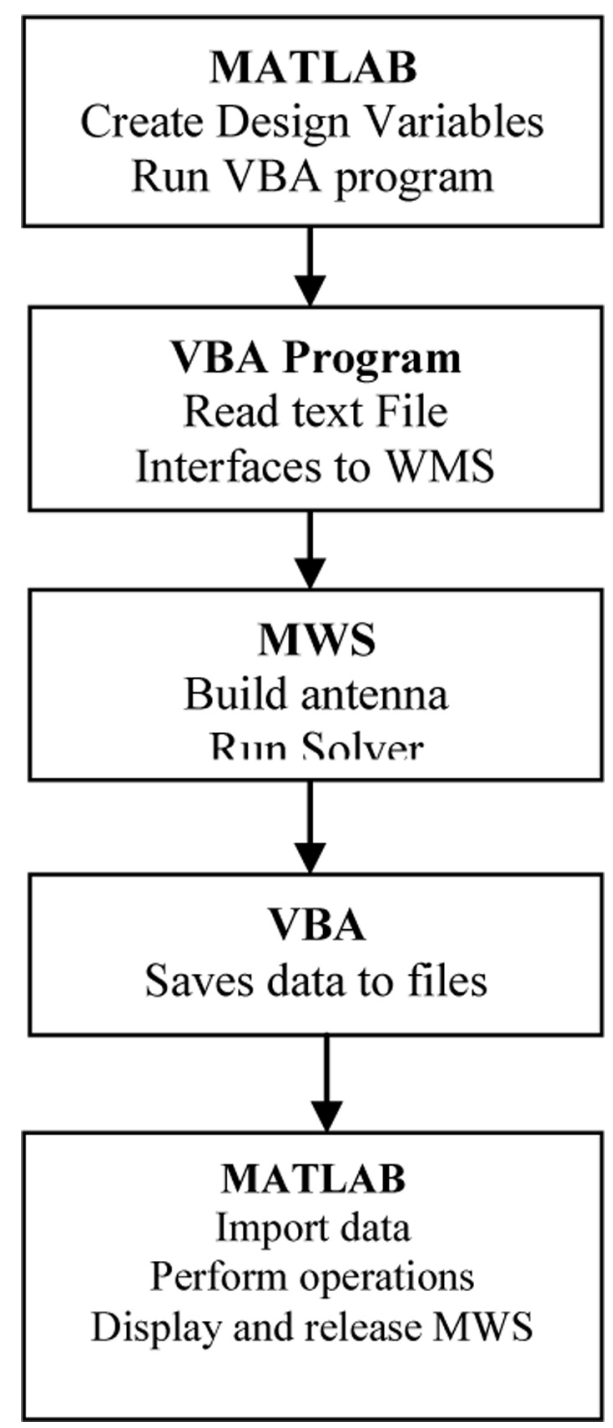

Figure 5. Flow chart for MATLAB-CST Interfacing ${ }^{11}$.

Before attempting to interface with MATLAB, it is a good idea to get familiar with the VBA editor. A microstrip patch antenna example is described in these papers which use MATLAB to control Microwave studio via VBA. Interfacing steps of MATLAB and CST are shown in Figure 5. With each run in microwave studio, a huge number of files are generated. The files posses same name but a different extensions. The relevant extensions ofparticular files are shown in Table 3.
Table 3. Different files used in interfacing and their extensions $\underline{1.2}$

\begin{tabular}{|c|c|}
\hline File name & Contents \\
\hline test1.m & MATLAB m file \\
\hline test.txt & ASCII file with variable values \\
\hline test1.bas & VBA program \\
\hline test1.mod & Microwave Studio model files \\
\hline test1^a1(1)1(1).sig & File containing $\mathrm{s}_{11}$ data \\
\hline
\end{tabular}

After invoking CST, the VBA program reads the data from test1.txt data file generated by MATLAB. The MWS file is opened once the data is read. When the scripting languages open the file, the commands in the script are executed. The next step is to start and save the solver using commands $\mathrm{in}^{\underline{11}}$ :

\section{! (solver.start')}

! save

! release

The microwave studio window closes automatically and control returns to MATLAB using release command, when the solver finishes and stores the data. Whenever the program is called from MATLAB the microwave studio window will reopen every time ${ }^{1,2}$. On running the MATLAB microwave studio interfacing algorithm resulted in $\mathrm{S}_{11}$ of value $-14.305 \mathrm{~dB}$ at $1.8 \mathrm{GHz}$ resonant frequency. The plot for $S_{11}$ parameter is illustrated in Figure 6.

Similarly using the result.dll directory and different text files generated during the simulation got saved in result of microstrip patch antenna, the value for performance parameters such as VSWR; return losses etc can be obtained. Interfacing of CST with MATLAB can be utilized for performing numerical optimization of antenna design using optimization algorithms such as $\mathrm{PSO}^{\stackrel{12,13}{2}}$.

\section{Conclusion and Future Scopes}

In this paper we have described how to interface MATLAB-microwave studio via VBA using an example of design of inset microstrip patch antenna of $1.8 \mathrm{GHz}$ of resonant frequency. With the advancement in the field of wireless communication system led to increase constraints on antennas. To achieve the desired goals antenna are typically designed by modifying existing design and often require cumbersome trial and error method. So the need for novel antenna design solution and strategies are 


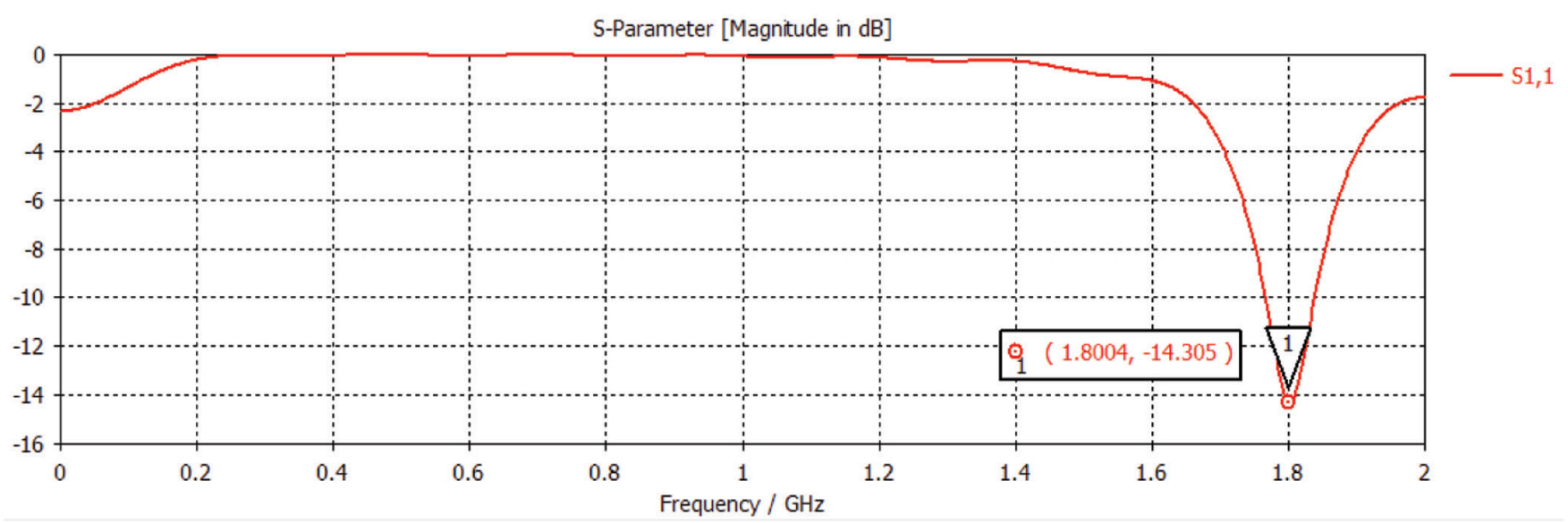

Figure 6. The Simulated plot for $\mathrm{S}_{11}$ Parameter ${ }^{2}$.

fulfilled by the amalgamation of existing full wave electromagnetic solvers with different optimization schemes.

The optimization is necessary as it offers more reliable results and higher chance of finding good solution when applied to a given designed problem in electromagnetic. A number of different algorithms have exploded every year to fulfill the high demand for robust optimization techniques. When the optimization is applied in real time (that is invoking CST using MATLAB) generates global optimum run for the given problem. In future we will employ the PSO[6] (Practical Swarm Optimization) on the above example of the microstrip patch antenna as PSO is high performance evolutionary algorithm capable of searching the solution space very differently and exploring new territory in multi model problems. Through Optimization algorithms goals can be easily achieved.

\section{References}

1. MATLAB Version R2016a. 2016. www.mathworks.com

2. CST Microwave Studio. Version 2014. 2016. www.cst.com

3. Yaqeen S, Mezaal. New compact microstrip patch antenna: Design and simulation results. Indian Journal of Science and Technology. 2016 Mar; 9(12):85950-6.

4. Anusuya A, Janetstephy J, Jegan G. Survey on various design of microchip patch antenna. American Journal of Engineering Research. 2014; 3(11):109-17.

5. Mosig JR. Microstrip antenna papers in IEEE Transactions on Antennas and Propagation. IEEE Antennas and Propagation Magazine. 2012; 54(1):264-8. Crossref.
6. Peixerio C. Microstrip patch antenna. A historical perspective of the development. Portugal: Inatituto de Telecommunicacoes Technical University of Lisbon; 2011. p. 684-8. Crossref.

7. Nisha AS. Hybrid coupled feed circularly polarized patch antenna for military application. Indian Journal of Science and Technology. 2015; 8(29):63684-7.

8. Balanis CA. Antenna theory analysis and design. NewYork: John Wiley and Sons; 1997.

9. Ramna, Sappal AS. Design of rectangular microstrip patch antenna using Particle Swarm Optimization. International Journal of Advance Research in Computer and Communication Engineering. 2013 Jul; 2(7):2918-20.

10. Saurabh AK, Kumar S, Srivastava DK. Design and bandwidth enhancement of rectangular microstrip patch antenna using double $\mathrm{H}$-slot technique for broadband applications. International Journal of Advanced Research in Computer and Communication Engineering. 2013; 2(12):4570-4.

11. Haupt RL. Using MATLAB to control commercial computational electromagnetics software. ACES Journal. 2008; 23(1):98-103.

12. Behera SK, Choukiker Y. Design and optimization of dual band microstrip antenna using Particle Swarm Optimization technique. U Springer Science and Business Media, LLC; 2010 Sep. p. 1346-54.

13. Rahmat-Samit Y. Natured inspired optimization technique in communication antenna design. Proceeding of IEEE. 2012 Jul; 100(7):2132-44. Crossref. 